\title{
An evaluation of weld metal nitrogen retention and properties in 316LN austenitic stainless steel
}

\author{
A M Galloway ${ }^{1 *}$, N A McPherson ${ }^{2}$, and T N Baker ${ }^{1}$ \\ ${ }^{1}$ Department of Mechanical Engineering, University of Strathclyde, Glasgow, UK \\ ${ }^{2}$ BAE Systems Surface Ships Ltd, Glasgow, UK
}

The manuscript was received on 16 September 2010 and was accepted after revision for publication on 7 January 2011.

DOI: $10.1177 / 1464420711398608$

\begin{abstract}
A series of tests were conducted using varying levels of nitrogen and helium in a conventional argon shielding gas when welding 316LN austenitic stainless steel. The outcome was that a 15 per cent nitrogen addition to the argon shielding gas had the most significant effect on increasing the weld metal nitrogen. Subsequent additions of helium to the argon 15 per cent nitrogen shielding gas had very little overall benefit. Increasing the nitrogen content of the weld metal had the consequential effects of decreasing the ferrite content and the hardness. As a result of solid solution strengthening, the yield strength increased with increase in nitrogen content. There was an increase in impact toughness as the nitrogen content increased. This was related to the decreased ferrite content associated with the strong austenetizing potential of nitrogen. It was also shown that an almost fully austenitic weld metal could still have very good toughness. In combination with these effects there was no loss in corrosion resistance. The addition of nitrogen to a conventional argon shielding gas presents attractive cost and quality benefits over the established requirement to over alloy the weld filler material with expensive alloys such as nickel.
\end{abstract}

Keywords: welding, stainless steel, nitrogen, helium, nuclear, shipbuilding

\section{INTRODUCTION}

The application of $316 \mathrm{LN}$ as a structural material is widespread among several industrial sectors including nuclear, cryogenic, shipbuilding, and defence where its advanced properties over conventional 3xxx series grades are well recognized. Arc welding of nitrogenenriched austenitic stainless steel creates a situation where the parent material adjacent to the weld zone loses nitrogen, resulting in a marked difference in composition between the parent plate and the weld metal. This occurs in part due to dilution effects between the parent plate and the weld metal, which typically has negligible nitrogen content, and in part due to desorption of nitrogen from the molten material. Nitrogen loss occurs if the partial pressure of nitrogen in the arc plasma is low and if certain other weld process conditions are present [1]. For example,

\footnotetext{
* Corresponding author: Department of Mechanical Engineering, University of Strathclyde, 75 Montrose St, Glasgow G1 1XJ, UK. email::alex.galloway@strath.ac.uk
}

a slow travel speed and high heat input will accelerate the overall nitrogen loss, and this reduction in the nitrogen will lead to a localized reduction of corrosion resistance and reduced mechanical properties.

Nitrogen is an established austenite stabilizer and it has particular benefits in improving the corrosion resistance and strength of austenitic stainless steel [2]. There is therefore good justification to maintain the initial parent plate levels of nitrogen and also to control the nitrogen absorption/desorption rates in the fusion zone during welding.

In currently accepted practice, the reduced levels of nitrogen expected in the weld metal are normally compensated by increasing the nickel content of the filler wire, as nickel is also an austenite stabilizer. Typically, relative parent plate and filler wire nickel contents would be set at 10 per cent and 12.5 per cent, respectively [3]. However, there is evidence that decreasing the nickel content increases the solubility of nitrogen in the weld metal [1]. In particular, this has been found to be beneficial in the superduplex grades of steel. In other highly alloyed stainless steels it has been reported [4] that increasing the nitrogen 
content reduces the formation of intermetallic phases and has no adverse effects on toughness or ductility. These effects are considered to result from the solid solution strengthening effects of nitrogen in austenitic stainless steel. Hence, the conventional approach in terms of increasing nickel content in the consumable has some contra-indications.

Nickel is an expensive element, and its increasing use in steelmaking and weld fabrication processes can also create significant cost increases. Therefore, alternative forms of austenite stabilization of the weld metal, such as enhancing the weld metal nitrogen content by using carefully blended nitrogen-rich shielding gases $[\mathbf{3}, \mathbf{5}]$, are an attractive option, particularly from a cost perspective.

\section{PREVIOUS INVESTIGATIONS}

\subsection{Nitrogen solubility effects}

Theoretically, the equilibrium solubility of nitrogen in pure iron alloys obeys Sievert's law, which shows that nitrogen concentration in liquid iron is proportional to the square root of the nitrogen partial pressure above the liquid as shown in equation (1)

$$
N=K\left(\mathrm{pN}_{2}(\text { gas })\right)^{1 / 2}
$$

where $N$ is the wt\% of nitrogen dissolved in the weld metal, $K$ is the reaction constant for equation (1), and $\mathrm{pN}_{2}$ is the partial pressure of nitrogen in the shielding gas.

Arc welding is known to be a complex dynamic process which is far removed from the established theories of nitrogen behaviour in the steelmaking industry. In the case of the latter, Sievert's law is used to predict the melt nitrogen level with some accuracy. Although it is generally agreed that Sievert's law fails to predict the resultant nitrogen with accuracy in the case of the arc welding processes, it nevertheless provides some guidance $[\mathbf{5}-\mathbf{8}]$. There is also reasonable agreement [3-5] to show that increasing the nitrogen partial pressure of the shielding gas minimizes nitrogen desorption during welding.

Shankar et al. [7] produced data to show that the weld metal nitrogen content did not follow Sievert's law during gas tungsten arc welding (GTAW), but was proportional to the nitrogen partial pressure in the shielding gas. Work by Mudali et al. [8] showed that about 6 per cent nitrogen in a conventional argon shielding gas could result in a nitrogen content of 0.15 per cent in 316 austenitic stainless steel without the occurrence of degassing. However, degassing was reported in the work of Du Toit and Pistorius [5]. Mudali et al. [8] also showed that 304 austenitic stainless steel has a greater potential to absorb nitrogen than the 316 grade. To achieve 0.15 per cent nitrogen content in the 304 weld metal a shielding gas nitrogen content of only 3 per cent could be employed. However, the reason for this difference in response could be related to the lower nickel content of the 304-grade steel (approximately 8 per cent nickel).

Recent work by Zhao et al. [9] on high-nitrogen steel $(\sim 0.56$ per cent nitrogen) concluded that the weld metal nitrogen content increases with raised nitrogen levels in the shielding gas, for the same heat input. Increasing heat input also had the effect of increasing the weld metal nitrogen content for shielding gas nitrogen levels greater than 2 per cent. In the case where pure argon shielding gas was used, the nitrogen content of the weld metal decreased with higher heat input levels.

Other work reported by Woo and Kikuchi $[\mathbf{1}]$ showed that the following welding factors affect nitrogen absorption and retention after welding:

(a) increased arc length when using shielded metal arc welding (SMAW) process;

(b) increased welding speed in the GTAW process when welding stainless steel;

(c) increasing welding voltage when using the fluxcored arc welding (FCAW) process;

(d) decreased welding current when using the FCAW process.

Subtle variations in the above welding process variables are known to influence the weld metal shape in terms of penetration depth and/or pool width $[\mathbf{1 0}, \mathbf{1 1}]$. From a study by Hertzman and Wessman [12] it was concluded that, among other factors, the weld pool geometry strongly influences the nitrogen flux of the weld and the plasma regions (e.g. control of the weld parameters to encourage the formation of a reduced surface area weld pool minimized the desorption of nitrogen from the liquid weld metal).

\subsection{Helium additions}

Helium, if added in small proportions to conventional argon shielding gas, is known to increase the arc temperature due to its increased ionization potential [13]. This was demonstrated by comparing the temperatures in different zones of the arc plasma within a 200A GTAW weld under pure argon and pure helium shielding conditions. In that particular work, the temperature data recorded for helium gas shielding were found to be significantly higher than for argon shielding. Helium was also shown to produce a narrower arc column than argon and, as this phenomenon resulted in a narrower weld pool area, the level of nitrogen desorption would be reduced, as discussed previously. The potential benefit of this arc temperature rise, based on the effects of helium, lies in the increased level of monatomic nitrogen available for absorption by the weld following the subsequent dissociation of diatomic nitrogen from the shielding gas. 
For example, Kuwana et al. [14] reported on the relationship between nitrogen absorption and temperature in a study of $\mathrm{Cr}-\mathrm{Ni}$ alloys and concluded that the level of monatomic nitrogen, produced as a thin layer on the surface of the weld to control the nitrogen equilibrium between the weld and this layer, increases as the arc temperature rises. As a result, the rise in temperature leads to an increase in the level of monatomic nitrogen available for absorption by the weld metal. However, it may be the case that the true benefit of this mechanism may only be realized in the higher nitrogen grades of austenitic stainless steels where increased levels of monatomic nitrogen would be essential in maintaining nitrogen flux between the weld pool and the arc plasma.

\subsection{Solidification modes and cracking propensity}

It has been accepted in conventional welding practice that the ferrite content of austenitic weld metal should be maintained at approximately 5 per cent [15]. Initially, this was considered to be essential to reduce the potential for solidification cracking. Work by Kujanpää and Moisio [16] led to the development of a cracking predictive relationship between $\mathrm{Cr}_{\text {eq }} / \mathrm{Ni}_{\mathrm{eq}}$ and $(\% \mathrm{P}+\% \mathrm{~S})$. This work [16] predicted that solidification cracking could be avoided with the correct combination of chromium and nickel equivalents and phosphorus and sulphur contents.

Another criterion that affects the suitability of welds for service is the primary solidification mode (PSM). This is normally determined [17] from a chromium equivalent-nickel equivalent relationship where

$$
\begin{aligned}
\mathrm{Cr}_{\text {eq }}= & \mathrm{Cr}+1.37(\% \mathrm{Mo})+1.5(\% \mathrm{Si}) \\
& +2(\% \mathrm{Nb})+3(\% \mathrm{Ti}) \\
\mathrm{Ni}_{\text {eq }}= & \mathrm{Ni}+0.31(\mathrm{Mn})+22(\% \mathrm{C}) \\
& +14.2\left(\% \mathrm{~N}_{2}\right)+\mathrm{Cu}
\end{aligned}
$$

and the $\mathrm{Cr}_{\text {eq }} / \mathrm{Ni}_{\text {eq }}$ ratio determines the PSM on the following basis:

$>2.0$ single-phase ferrite $(\mathrm{F})$

$>1.5<2.0$ ferritic-austenitic (F-A)

$<1.5$ austenitic-ferritic or single-phase austenite (A-F) or (A)

A further consideration is the relationship between the effects of cooling rate on the PSM [17]. However, the ranges shown above can be used for indicative purposes in this type of work. The main issue is that welds that solidify as primary ferrite $\left(\mathrm{Cr}_{\mathrm{eq}} / \mathrm{Ni}_{\mathrm{eq}}>1.5\right)$ are less susceptible to solidification cracking than welds that solidify as primary austenite [18].

The foregoing review suggests that the incorporation of nitrogen in the shielding gas could provide an effective and economic route to maintaining desirable properties in nitrogen-bearing austenitic steel weld joints, but there are some uncertainties and conflicting results that merit deeper investigation.

\section{PRESENT INVESTIGATION}

Although a new model to account for the nitrogen behaviour in complex systems such as the plasma of a welding arc is not the objective of the present study, the aim of this experimental programme is to evaluate the effects of different argon, nitrogen, and helium shielding gas mixtures in welding AISI 316LN material and, in particular, to determine the outcomes with respect to final nitrogen levels in the completed weld joints. To allow an accurate evaluation to be reported with respect to weld metal nitrogen retention and properties, the experimental programme allowed multiple weldments to be produced under strictly controlled conditions to ensure that repeatability of welding conditions were assured. The following error analysis was determined and applied to all mechanical property data to account for experimental variation

$$
\sigma_{x}=\sqrt{\frac{1}{N} \sum_{i=1}^{N}\left(d_{i}\right)^{2}}=\sqrt{\frac{1}{N} \sum_{i=1}^{N}\left(x_{i}-\bar{x}\right)^{2}}
$$

where $\sigma_{x}$ is the standard deviation, $N$ is the number of values recorded, and $X_{i}$ is the measured value, giving $\sigma_{x}=1.95$ per cent for hardness testing, $\sigma_{x}=4.82$ per cent impact testing, and $\sigma_{x}=5.31$ per cent tensile testing.

\subsection{Base material and shielding gases}

The base metal used throughout this study was a commercial-grade AISI 316LN $12 \mathrm{~mm}$ thick plate. This is a low-carbon, nitrogen-enriched, molybdenumbearing, austenitic stainless steel. Tables 1 and 2 show the chemistry and the mechanical property data for the plate and filler wire materials. Table 3 shows the composition of the shielding gases used in the study, the analysis of which was validated prior to use. A shielding gas flowrate of $181 / \mathrm{min}$ was used throughout the study.

The base shielding gas (Type 1) was 100 per cent argon. Type 2 shielding gas, comprising 85 per cent argon/ 15 per cent nitrogen, was chosen to evaluate the effect of nitrogen additions on the weld metal nitrogen content. The other two gases (Type 3 and Type 4) contained 15 per cent nitrogen and two different levels of helium, namely 5 per cent and 20 per cent. This allowed the effect of helium to be determined on the nitrogen absorption of the weld metal. 
Table 1 Plate and filler material composition

\begin{tabular}{|c|c|c|c|c|c|c|c|}
\hline \multicolumn{8}{|c|}{ Chemical composition (wt\%) } \\
\hline $\mathrm{C}$ & $\mathrm{Si}$ & $S$ & $\mathrm{P}$ & $\mathrm{Mn}$ & $\mathrm{Ni}$ & $\mathrm{Cr}$ & Mo $\mathrm{N}$ \\
\hline
\end{tabular}

$\begin{array}{llllllllll}\text { AISI 316LN } & 0.013 & 0.51 & 0.007 & 0.024 & 1.15 & 10.1 & 17.37 & 2.7 & 0.13\end{array}$ $\begin{array}{lllllllllll}316 \mathrm{~L} \text { (filler) } & 0.016 & 0.51 & 0.005 & 0.019 & 1.81 & 12.4 & 19.00 & 3.0 & 0.03\end{array}$

Table 2 Plate and filler material properties

\begin{tabular}{|c|c|c|c|c|c|}
\hline & \multicolumn{5}{|c|}{ Typical mechanical properties } \\
\hline & $\begin{array}{l}\text { Vickers } \\
\text { Hardness } \\
\text { Number } \\
\text { (VHN) }\end{array}$ & $\begin{array}{l}\text { UTS } \\
\text { (MPa) }\end{array}$ & $\begin{array}{l}\text { Yield } \\
\text { (MPa) }\end{array}$ & $\begin{array}{l}\text { Charpy } \\
\text { impact } \\
\left(+20^{\circ} \mathrm{C}\right)\end{array}$ & $\begin{array}{l}\text { Charpy } \\
\text { impact } \\
\left(-200^{\circ} \mathrm{C}\right)\end{array}$ \\
\hline $\begin{array}{l}\text { AISI } \\
\quad 316 \mathrm{LN}\end{array}$ & 217 & 685 & 205 & $260(\mathrm{~J})$ & $70(\mathrm{~J})$ \\
\hline $\begin{array}{l}316 \mathrm{~L} \\
\quad \text { (filler) }\end{array}$ & 185 & 480 & 365 & $100(\mathrm{~J})$ & $45(\mathrm{~J})$ \\
\hline
\end{tabular}

\subsection{Welding procedure and joint detail}

The first stage of the experimental work centred on using autogenous GTAW to assess factors such as weld width and depth as a function of shielding gas composition. Thereafter, the work focused on the use of fully automatic gas metal arc welding (GMAW) to establish relationships between shielding gas composition and the nitrogen content of the weld metal, the mechanical properties of the welds, and the microstructure of the weld metal.

The GMAW welds were produced using a $1.2 \mathrm{~mm}$ diameter solid filler wire of the composition shown in Table 1. This shows a 20 per cent level of nickel overmatching relative to the parent plate composition. Welding parameters were in the range $23-25 \mathrm{~V}$ and 225-300 A, with electrode positive polarity, resulting in a spray transfer mode. The welding speed was $110 \mathrm{~mm} / \mathrm{min}$, and this resulted in heat inputs of $3.26 \mathrm{~kJ} / \mathrm{mm}$ approximately. The weld edge preparation was manufactured to give a $60^{\circ}$ inclusive angle with a $2.5 \mathrm{~mm}$ root face and a $2 \mathrm{~mm}$ root gap, and a ceramic backing tile was applied below the root face. Five weld passes were made to complete the joint.

\subsection{Instrumentation and temperature measurement}

Welding process variables were monitored using a portable arc monitoring system data acquisition unit. This allowed continuous measurement of the main variables, including energy consumption and weld heat input. Non-contact and contact temperature measurements were made using thermographic imaging and traditional thermocouple methods. The thermographic camera used in this study was a ThermoCAM $^{\mathrm{TM}}$ SC500 manufactured by FLIR Systems which measures infrared radiation at wavelengths in the range of 7.5-13 $\mu \mathrm{m}$. Thermocouple groupings ( $\mathrm{K}$ type) were attached at predetermined locations on the upper and lower surfaces of the plate within a spatial tolerance of $1 \mathrm{~mm}$. The thermocouples were connected to a multiplex unit, where the temperatures were recorded by pre-programmed software.

\subsection{Weld nitrogen measurement}

Sections of parent plate and weld metal $(25 \times 25 \mathrm{~mm})$ were cut parallel to the weld direction using a Struers Accutom-5 cut-off machine. Samples were then removed at a depth of $2 \mathrm{~mm}$ from the plate surface followed by subsequent cutting procedures to produce individual fibres $\left(1 \mathrm{~mm}^{2}\right)$, which were accurately cut from the fusion and heat-affected zone as shown in Fig. 1. A coolant mist was applied to the samples during cutting. The disc rotational speed was $3000 \mathrm{r} / \mathrm{min}$ and the feed rate was $0.04 \mathrm{~mm} / \mathrm{s}$. Unlike the conventional hole drilling method, this particular technique ensures compositional consistency along the length of each sample. The analysis was carried out using Leco TC136 equipment, where the nitrogen released was measured via a thermal conductivity cell.

\subsection{Ferrite measurement}

Two methods of ferrite measurement were used, namely standardized magnetic induction methods to ANSI/AWS A4.2:1997 and image analysis techniques. For the induction methods, the instrument was calibrated using accepted industry standards regulated by

Table 3 Shielding gas compositions, proportional ionization potentials, and average peak plate temperatures ( $15 \mathrm{~mm}$ from edge of weld)

\begin{tabular}{|c|c|c|c|c|c|c|c|}
\hline Gas type & $\begin{array}{l}\mathrm{Ar} \\
\text { (vol\%) }\end{array}$ & $\begin{array}{l}\mathrm{N}_{2} \\
\text { (vol\%) }\end{array}$ & $\begin{array}{l}\mathrm{He} \\
\text { (vol\%) }\end{array}$ & $\begin{array}{l}\mathrm{PIP}^{*} \\
(\mathrm{eV})\end{array}$ & $\begin{array}{l}\text { Increase in } \\
\text { PIP* } \\
\text { compared } \\
\text { to Type } 1\end{array}$ & $\begin{array}{l}\text { Average } \\
\text { peak } \\
\text { temperature } \\
\left({ }^{\circ} \mathrm{C}\right)\end{array}$ & $\begin{array}{l}\text { Increase } \\
\text { in peak } \\
\text { temperature } \\
\text { compared } \\
\text { to Type } 1\end{array}$ \\
\hline Type 1 & 100 & 0 & 0 & 1575 & & 355 & \\
\hline Type 2 & 85 & 15 & 0 & 1703 & 8.1 & 386 & 8.7 \\
\hline Type 3 & 80 & 15 & 5 & 1746 & 10.86 & 415 & 16.9 \\
\hline
\end{tabular}

*Proportional ionization potential. 


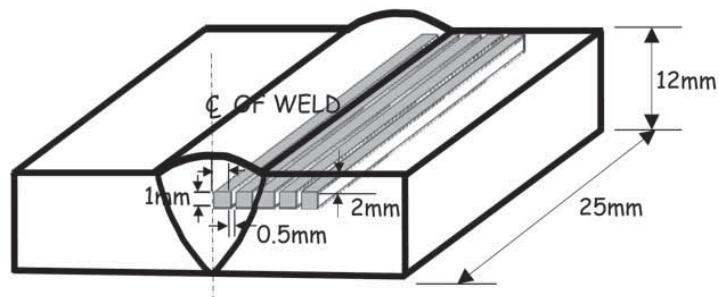

Fig. 1 Nitrogen analysis showing sample removal positions

the International Institute of Welding. In this respect the instrument was calibrated against a standard block to ensure measurement accuracy of at least 99.95 per cent. Probe measurements were taken along the length of each weld sample to determine the volume percentage of $\delta$-ferrite at each location point. Image Pro-Plus Version 4.0 was used to identify phase variations following colour etching of the prepared samples. Measurements were recorded in both transverse and longitudinal directions relative to the weld region. The software was programmed to recognize areas of known $\delta$-ferrite within the austenite matrix, before systematic calculation of the volume percentage of this second phase in a selected region.

\subsection{Microstructural evaluation}

Samples were extracted from the weld zone and prepared using standard optical and transmission electron microscopy (TEM) methods. Specimens were removed from the weld centre and heat-affected zone for subsequent thin foil preparation and investigation. Thin sections $(0.5 \mathrm{~mm})$ were cut from the bulk specimen using a Struers Accutom- 5 cutting machine. Sections were removed transverse to the weld direction allowing $3 \mathrm{~mm}$ diameter discs to be removed from selected regions using a Metalthin Spark Erosion machine. The discs were then mechanically thinned to $100 \mu \mathrm{m}$ before subsequent electrolytic etching and perforation by standard jet polishing methods. The foils were examined using a Philips EM 400T transmission electron microscope at an operating voltage of $80-100 \mathrm{kV}$. Spectral analysis (quantitative and qualitative) was carried out using an energy dispersive X-ray spectroscopy (EDS) detector.

\subsection{Mechanical, corrosion testing and solidification cracking resistance}

Mechanical testing was carried out using standard techniques. Corrosion resistance was assessed using the Strauss test (BS EN ISO 3651-2). Solidification cracking resistance was determined using a circular patch test. This test procedure, which is explained in detail elsewhere [19] is commonly used to evaluate the susceptibility of steels and aluminium alloys to solidification cracking as a result of induced shrinkage stresses which occur during solidification under severe restraint conditions. Following GMAW with each experimental shielding gas, the circular test samples were naturally cooled and examined in four regions using an optical microscope at $\times 400$ magnification.

\section{RESULTS AND DISCUSSION}

\subsection{Effect of GTAW welding parameters on weld geometry and nitrogen content}

The preliminary work using GTAW showed that nitrogen addition had very little effect on the weld depth or width. The addition of 5 per cent helium to the gas had a slight effect in increasing the depth and decreasing the width. However, the 20 per cent helium addition had a significant effect (Fig. 2) on both weld depth and width, producing the narrowest and deepest weld for the gas shielding mixtures used. This has already been seen in other work as a significant effect $[\mathbf{1}, \mathbf{5}, \mathbf{6}]$.

Other factors established as influencing nitrogen content were as follows.

1. At fixed voltage and current, increased travel speed (i.e. decreased specific heat input), resulted in less nitrogen desorption.

2. Increased arc length, with all other factors unchanged, resulted in significant nitrogen desorption.

3. A slight desorption effect was evident for all nitrogen-containing shielding gases at sampling positions nearer the parent plate.

These findings are in relatively good agreement with most published data $[\mathbf{1}, \mathbf{3}, \mathbf{1 1}-\mathbf{1 3}]$, but not with those of Du Toit and Pistorius [5], where the findings were contrary to those of the present study.

\subsection{Effect of shielding gas composition on nitrogen content in GMA welds}

The data shown in Fig. 3 suggest different trends. For 100 per cent argon shielding the lowest level of nitrogen is seen at the weld centre, although even here

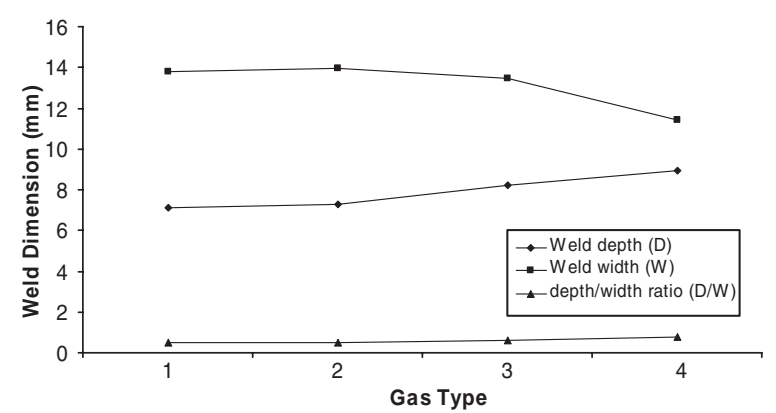

Fig. 2 Weld geometry following autogenous GTAW welds (see Table 3 for gas types) 


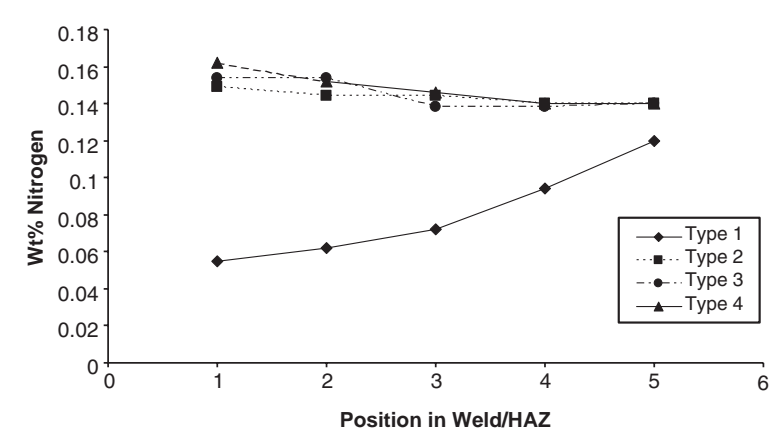

Fig. 3 Nitrogen levels following GMAW welds with each gas type (Position 1 at weld centre) (see Table 3 for gas types)

there has been a slight contribution from the dilution of the parent plate. As the analysis position is moved away from the centre-line, the nitrogen content increases due to the progressive effects of parent plate dilution.

All of the gas mixtures show very similar effects. In fact, the nitrogen levels are identical in the parent plate region, although the mixture with 20 per cent helium addition shows a marginally higher nitrogen level at the weld centre position. This is possibly a function of the weld geometry, as the smaller weld surface area allows less molten surface for the gas to escape and the deeper weld also increases the level of parent plate dilution. A similar effect has been postulated by Zhao et al. [9], but apparently not verified. Using the 100 per cent argon shielding gas as the base case, the nitrogen increase in the weld metal for each of the shielding gases is shown below:

(a) 15 per cent nitrogen (82 per cent);

(b) 15 per cent nitrogen/5 per cent helium (91 per cent);

(c) 15 per cent nitrogen/20 per cent helium (98 per cent).

This shows clearly the very significant effect of nitrogen addition and the secondary effects of helium. In all cases no degassing was observed for the welds produced and this may only be an effect with the high nitrogen steels (0.56 per cent nitrogen) [9]. Zhao et al. [9] found that the nitrogen content in the weld increased with increase in nitrogen content of the shielding gas, for the same heat input, and increase in heat input at constant nitrogen content in the shielding gas resulted in an increase in weld metal nitrogen. For the current work it has been established that the level of 0.162 per cent nitrogen is close to the nitrogen solubility limit for the steel used in the study.

\subsection{Effect of shielding gas composition on plate temperature}

If the theory related to helium increasing the arc temperature is correct, then the plate temperature should be higher than that of plates without helium. Table 3 shows the peak temperature measured when each shielding gas was being used. Also included is the percentage increase in the peak temperature when compared against the base case (i.e. Type 1). There is quite clearly a trend which shows that helium has an effect on peak temperature and this would be expected based on the findings of Jonsson et al. [13].

However, from Type 1 to Type 2 gas there is also a temperature rise, which must be related to the 15 per cent nitrogen addition to the shielding gas. This effect of nitrogen on plate temperature was unexpected, and the ionization temperatures for each gas were proportionalized for each gas mixture, using 24.58, 24.3, and $15.75 \mathrm{eV}$ for helium, nitrogen, and argon, respectively. The increase in the proportional ionization potential for each mixture against the base case of the Type 1 shielding gas is shown in Table 3, and there is reasonable agreement with the percentage increases between peak temperature and proportional ionization potential. It appears that nitrogen has a similarly beneficial effect of increasing the arc temperature as helium. This has important implications for the economics of welding stainless steel, as the most cost-effective solution may be to leave helium out of the mixture. Based on the work of Zhao et al. [9] there may even be benefits in reducing the nitrogen content in the shielding gas, as a plateau effect is seen at the higher heat input tests.

\subsection{Microstructural assessment}

The data on $\delta$-ferrite levels for each case are shown in Fig. 4. This is an expected trend and is in line with the work of Woo and Kikuchi [1]. This figure clearly shows the austenite stabilization effects of increased nitrogen in the weld metal. Using the data in Table 4 to calculate the $\mathrm{Cr}_{\text {eq }}$ and $\mathrm{Ni}_{\text {eq }}$ factors and then plotting these onto a DeLong [20] constitution diagram, good agreement was obtained between the predicted $\delta$-ferrite and the measured $\delta$-ferrite for each shielding gas.

The PSM is known to be influential in affecting solidification cracking in austenitic stainless steels.

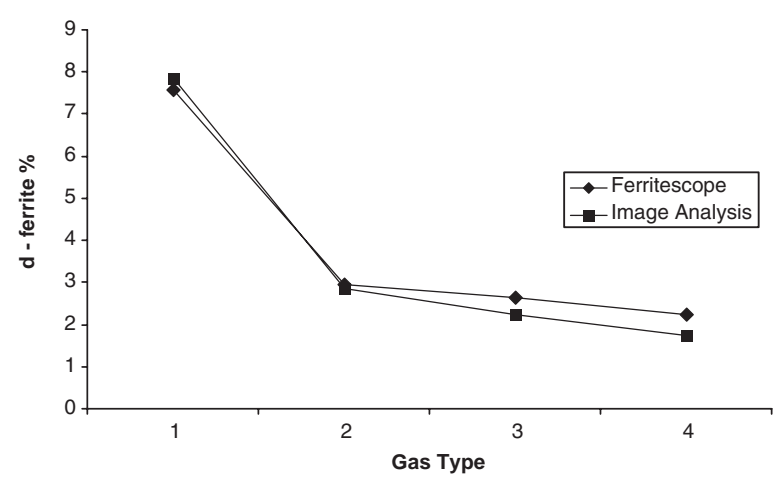

Fig. 4 Delta ferrite levels following GMAW with each gas type (see Table 3 for gas types) 
Table 4 Average weld metal composition, PSM, and Cr/Ni equivalents values following GMAW

\begin{tabular}{|c|c|c|c|c|c|c|c|c|c|c|c|c|c|}
\hline \multirow[b]{2}{*}{ Gas type } & \multicolumn{9}{|c|}{ Chemical composition (wt\%) } & \multicolumn{2}{|c|}{ Kujanpää and Moisio [16] } & \multicolumn{2}{|c|}{ Long and Delong [20] } \\
\hline & $\mathrm{Si}$ & Mo & Mn & $\mathrm{Cr}$ & $\mathrm{Ni}$ & $\mathrm{C}$ & $\mathrm{N}$ & $\mathrm{P}$ & $S$ & $\mathrm{Cr} / \mathrm{Ni}_{\mathrm{eq}}$ & PSM & $\mathrm{Cr}_{\mathrm{eq}}$ & $\mathrm{Ni}_{\mathrm{eq}}$ \\
\hline Type 1 & 0.5 & 2.9 & 1.5 & 17.8 & 11.5 & 0.013 & 0.077 & 0.018 & 0.01 & 1.66 & F-A & 21.45 & 14.95 \\
\hline Type 2 & 0.6 & 2.9 & 1.4 & 17.4 & 11.7 & 0.013 & 0.14 & 0.018 & 0.01 & 1.57 & F-A & 21.2 & 16.9 \\
\hline Type 3 & 0.6 & 2.9 & 1.4 & 17.5 & 11.7 & 0.013 & 0.147 & 0.018 & 0.01 & 1.56 & F-A & 21.3 & 17.2 \\
\hline Type 4 & 0.6 & 2.9 & 1.4 & 17.7 & 11.6 & 0.013 & 0.153 & 0.018 & 0.01 & 1.56 & F-A & 21.5 & 17.28 \\
\hline
\end{tabular}

Prediction of the PSM can be made using the regression equations developed by Kujanpää and Moisio [16]. In each weld tested using the patch test [19] there was no indication of cracking. This would be expected as the PSM for each weld fell into the category of ferritic-austenitic (F-A). Although this effect has to be considered with the low levels of $\delta$-ferrite shown in Fig. 4, it may be related to the combined effect of PSM and the lower sulphur and phosphorus levels in the parent plate and filler wire as shown in Table 1. Reference to Fig. 5 [21] highlights the relationship between $\mathrm{Cr}_{\text {eq }} / \mathrm{Ni}_{\text {eq }}$ and (\%P $\left.+\% \mathrm{~S}\right)$, and the data from the current study are overlayed. Clearly, the welds produced using the shielding gases in the present study carry no risk of solidification cracking. It is therefore apparent that the previous well-established requirement, to have $\delta$-ferrite levels in the weld metal of 5 per cent minimum, is no longer a straightforward requirement. Further, in Kujanpää and Moisio's [16] work there was an example of a totally austenitic steel AISI310 steel that did not display any cracking but had a $(\% \mathrm{P}+\% \mathrm{~S})$ of 0.010 per cent.

Typical austenitic stainless-steel microstructures were observed, which showed regions of 8 per cent delta ferrite by volume for Type 1 shielding gas. Significantly lower levels of delta ferrite levels were observed for Type 2 and Type 3 gases, and an almost completely austenitic microstructure was revealed for Type 4 shielding gas. No evidence of intermetallic phases, carbides, or nitrides was seen in this investigation.

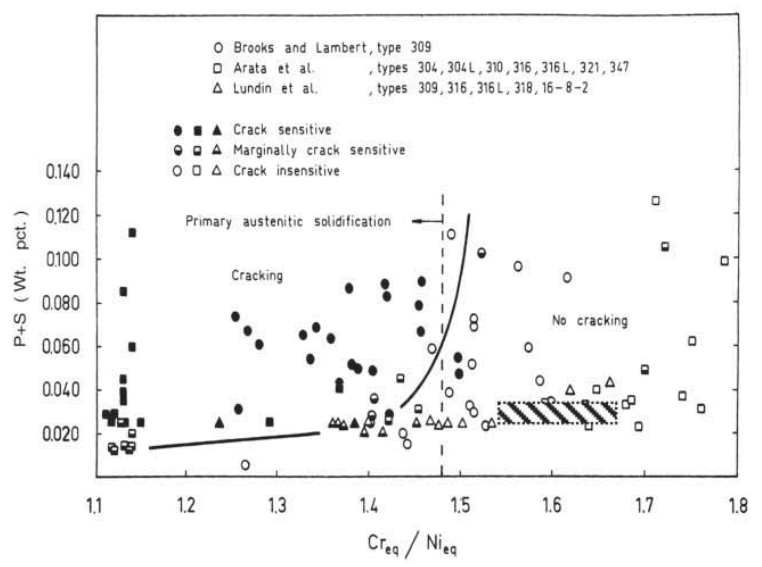

Fig. 5 Crack susceptibility plot [21] showing position of GMAW with each gas type (hatched region) (see Table 3 for gas types)
Finer detail of the microstructure was investigated using TEM and the significant role of nitrogen as an austenite stabilizer was confirmed.

\subsection{Mechanical properties}

The average longitudinal weld strength properties are shown in Fig. 6 and Table 5. There is a very clear relationship here on the effect of increasing the nitrogen content. The initial effect of the nitrogen on ultimate tensile strength (UTS) is not enhanced particularly by the helium addition, but the effect on yield strength shows a progressive increase against the base case. This is probably the evidence of solid solution strengthening effect of nitrogen, which is more powerful on yield strength than on ultimate tensile strength. In the case of austenitic stainless steels, it is known [22] that high nitrogen contents in solid solution can markedly increase the yield strength without an accompanying loss in fracture toughness. This is primarily caused by the crystal lattice distortion due to nitrogen atoms in interstitial positions.

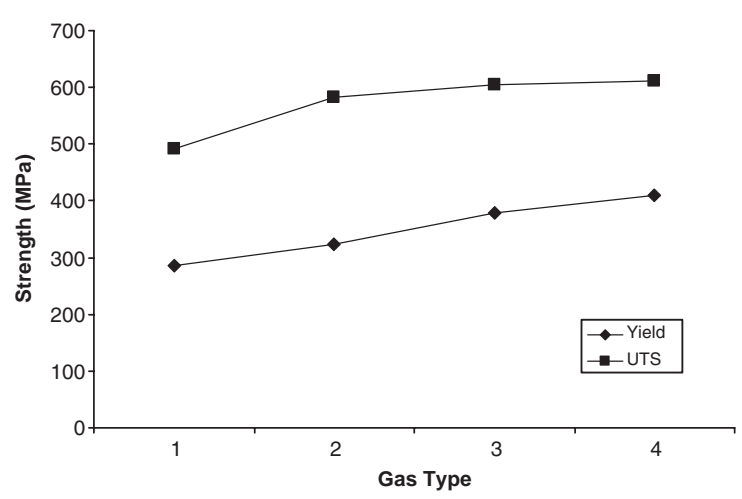

Fig. 6 Weld transverse strength data following GMAW with each gas type (see Table 3 for gas types)

Table 5 Transverse tensile data for each gas type

\begin{tabular}{lllll}
\hline & & & \multicolumn{2}{l}{$\begin{array}{l}\text { Increase against } \\
\text { Type 1 (\%) }\end{array}$} \\
\cline { 5 - 5 } Gas type & UTS (MPa) & YS (MPa) & UTS & YS \\
\hline Type 1 & 495 & 280 & & \\
Type 2 & 597 & 331 & 20 & 18 \\
Type 3 & 601 & 366 & 21.5 & 31 \\
Type 4 & 620 & 414 & 25 & 48 \\
\hline
\end{tabular}




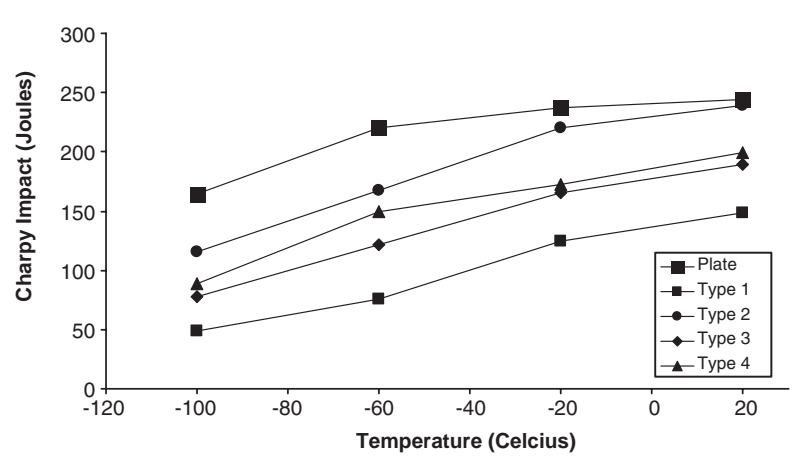

Fig. 7 Charpy impact data at various temperatures related to shielding gas type (see Table 3 for gas types)

Average impact toughness data are shown in Fig. 7. In all cases the weld metal toughness, as measured by Charpy impact absorption, is lower than the parent plate material but increased with increasing nitrogen retention and, hence, reduction in $\delta$-ferrite. The general behaviour seen is in line with the findings of Du Toit and Pistorius [5], who also observed an increase in weld metal toughness as the nitrogen content increased. This, in part, could be related to the reduction in the $\delta$-ferrite content as higher levels tend to decrease the toughness [2]. Further, there is some evidence [20] to show that fully austenitic weld metal can provide maximum toughness at cryogenic temperatures.

It is important to note that conventional fracture toughness testing of welded joints is complicated by the fact that the fusion zone and HAZ exhibits a heterogeneous microstructure that can have widely varying strength and toughness values. Hence, the Charpy V-notch impact test is the accepted method for toughness assessment of welded joints. As most alloy steels have toughness values that vary with temperature, tests on welded joints are often conducted at several temperatures and the absorbed energy or is plotted as a function of temperature.

\subsection{Summary of findings}

This work has highlighted the benefits of adding nitrogen to a conventional argon shielding gas during GMAW of 316LN plate and provides a cost effective alternative to the current industry practice of increasing the nickel content of the filler material. In terms of helium additions, there are relatively few benefits in adding helium to the shielding gas for welding austenitic stainless steel at the 15 per cent nitrogen base level, although there did appear to be a significant yield strength increase resulting from the small nitrogen increases in the two helium bearing gases. Based on the work carried out by Zhao et al. [9] and Du Toit and Pistorius [5], it may be beneficial to reduce the nitrogen content of the shielding gas to establish the minimum content at which the benefits are still obtained.

\section{CONCLUSIONS}

The addition of 15 per cent nitrogen to the conventional argon shielding gas significantly changes the weld metal properties due to an 82 per cent increase in the retained nitrogen content compared to the base case of 100 per cent argon. The additional nitrogen content of the weld metal resulted in lower ferrite content, lower hardness, better toughness, and no deterioration in cracking tendency. Compared to the current practice of specifying enhanced nickel levels as a means of controlling the weld metal austenite level, future consideration should be given to the lowercost option of using nitrogen-containing shielding gas. Further work is required to optimize the nitrogen level with respect to microstructure, properties, and solidification mode.

Although some beneficial effects were identified by the addition of helium to the argon/nitrogen gases, these were marginal in nature and would be economically ineffective as a nickel substitute.

\section{(C) Authors 2011}

\section{REFERENCES}

1 Woo, I. and Kikuchi, Y. Weldability of nitrogen stainless steel. ISIJ Trans., 2002, 40(12), 1334-1343.

2 Easterling, K. Introduction to the physical metallurgy of welding, 1985 (Butterworths, London).

3 Galloway, A. M. and McPherson, N. A. The effect of shielding gas composition on weld metal nitrogen retention in 316LN stainless steel. Weld. Cutt., 2006, 5(4), 225-230.

4 Hertzman, S. Highly alloyed stainless steels. Scand. J. Metall., 1995, 24, 140-146.

5 Du Toit, M. and Pistorius, P. C. Nitrogen control during autogenous welding of stainless steel - part 1: experimental observations. Weld. J., 2003, 82(8), 219s-224s.

6 Kuwana, T. and Kokawa, H. The nitrogen absorption of iron weld metal during gas tungsten arc welding. Trans. Jpn. Weld. Soc., 1986, 17(1), 20-26.

7 Shankar, V., Gill, T. P. S., Mannan, S. L., and Sundaresan, S. Solidification cracking in austenitic stainless steel welds. Sädhanā , 2003, 29(3 \& 4), 359-382.

8 Mudali, U. K., Dayal, R. K., Gill, T. P. S., and Gnanamoorthy, J. B. Influence of nitrogen additions on microstructure and pitting corrosion resistance of austenitic weld metals. Werkst. Korros., 1986, 37, 637-643.

9 Zhao, L., Tian, Z. L., and Peng, Y. Control of nitrogen content and porosity in gas tungsten arc welding of high nitrogen steel. Sci. Technol. Weld. Joint, 2008, 14(1), 87-92.

10 Heiple, C. R. and Roper, J. R. Effect of minor elements on GTA fusion zone shape. In Proceedings of the Conference 
on Trends in welding research in the United States, New Orleans, 16-18 November 1981, pp. 489-520.

11 Mills, K. C. and Keene, B. J. Factors affecting variable weld penetration. Int. Mater. Rev., 1990, 35(4), 187-216.

12 Hertzman, S. and Wessman, S. An experimental and theoretical study of nitrogen flux in stainless steel TIG welds. Mater. Sci. Forum, 1999, 318-320, 579-590.

13 Jonsson, P. G., Eager, T. W., and Szekely, J. Heat and metal transfer in gas metal arc welding using argon and helium. Metall. Mater. Trans. B, 1995, 26, 383-395.

14 Kuwana, T., Kokawa, H., and Saotome, M. Quantitative prediction of nitrogen absorption by steel during gas tungsten arc welding. In Mathematical Modelling of Weld Phenomena 3 (Ed. H. Cerjak), 1997, pp. 64-81 (The Institute of Materials, London).

15 Brooks, J. A. and Thompson, A. W. Microstructural development and solidification cracking susceptibility of austenitic stainless steel welds. Int. Mater. Rev., 1991, 36(1), 16-45.

16 Kujanpää, V. P. and Moisio, T. Effect of phosphorus and sulphur on solidification cracking in austenitic stainless steel. In Proceedings of the Solidification Technology in the Foundry and Cast House, Conference, The Metal Society, Coventry, UK, 1980, pp. 372-375.
17 Suutala, N. and Moisio, T. 1980. Use of chromium and nickel equivalents in considering solidification phenomena in austenitic stainless steels. In Proceedings of the Solidification Technology in the Foundry and Cast House, Conference, The Metal Society, Coventry, UK, pp. 310-314.

18 Elmer, J. W., Allen, S. M., and Eager, T. W. Microstructural development during solidification of stainless steel alloys. Metall. Trans. A, 1989, 20A, 2117-2131.

19 Nelson, T. W., Lippold, J. C., Lin, W., and Baeslack, W. A. Evaluation of the circular patch test for assessing weld solidification cracking, part 1 - development of a test method. Weld. J., 1997, 76(3), 110s-119s.

20 Long, C. J. and DeLong, W. T. The ferrite content of austenitic stainless steel weld metal. Weld. J., 1974, 53(7), 281s-297s.

21 Kujanpää, V. P., David, S. A., and White, C. L. Formation of hot cracks in austenitic stainless steel welds - solidification cracking. Weld. J., 1986, 63(4), 203s-212s (Weld. J., 1997, 76, 110S-119S).

22 Spiedel, M. O. High nitrogen stainless steels; austenitic, duplex and martensitic, September 1987, pp. 247-252 (Institute of Materials, London). 